\title{
Effectiveness of Sealants Treatment in Permanent Molars: A Longitudinal Study
}

\author{
Mimoza Canga ${ }^{1}$, Giulia Malagnino ${ }^{2}$, Vito A Malagnino ${ }^{3}$, Irene Malagnino ${ }^{4}$
}

\begin{abstract}
Background: Our study gives a clear result about sealants treatment in preventing dental caries manifestation and reducing its prevalence in children aged 6-11 years old.

Aim and objective: This study aims to compare and evaluate the progress of dental caries in the first and second permanent molars and also to evaluate, within a period of 24 months, the clinical effects of dental sealants, used in the treatment of occlusive cavities, among children 6-11 years old.

Materials and methods: Participants: The overall sample was composed of 120 children, to whom we randomly chose 480 posterior teeth, which were divided into two groups. Intervention: The first group was the control group with 240 untreated teeth, while the second group had an equal number of teeth, which underwent the sealant treatment. The study participants were evaluated within the periods $0,6,12,18$, and 24 months. The study participants were checked every 6 months. Basic design: This observational, analytical, and descriptive research was designed as a longitudinal study. The study started in January 2019 and ended in January 2020. The study was conducted in five dental clinics in the city of Vlore, Albania.

Results: After 24 months of observation, we noticed that the number of dental caries in the untreated group is three times higher than the number of dental caries in the treated group. In the group of teeth treated with sealant, $189(78.8 \%)$ teeth remained unaffected by dental caries. The present study showed that there is a significant correlation between period and caries manifestation $(p<0.05)$. It also proved that sealant treatment is an important measure and it is highly significant in the caries reduction $(p=0.000)$.

Conclusion: This study proved that sealant treatment is highly successful in reducing dental caries. In the future, it is worthwhile to go further in this research.

Clinical significance: Dental caries is a problem in children aged 6-11 years old and not only. That is why this study recommends that sealants treatment should be used to prevent and reduce the prevalence of dental caries.

Keywords: Dental caries, First and second permanent molar, Preventive dentistry, Sealant treatment.

International Journal of Clinical Pediatric Dentistry (2021): 10.5005/jp-journals-10005-1878
\end{abstract}

\section{INTRODUCTION}

In our survey, we have taken into consideration the progress of dental caries in the first and second permanent molars for the period of 24 months between children 6 years and 11 years old.

Based on the National Health and Nutrition Examination Survey 2011-2012, showed that 21\% of the children, aged 6-11 years old, were diagnosed with dental caries in their permanent teeth. While comparing these results to the same survey conducted in the period 1999-2004, a decline in the prevalence of caries in primary teeth and a minimal decrease in the caries percentage were noticed. ${ }^{1,2}$

About $90 \%$ of dental caries in permanent posterior teeth was found in pit and fissure. ${ }^{3}$

Fissures and holes, where organic waste and oral bacteria collect, are considered to be ideal places for caries development. ${ }^{4-7}$

Nowadays, data show that sealants are effective in children with a high risk of caries. ${ }^{8-11}$ Sealant application is a preventive conservative approach in caries reduction. It fills the teeth surface, as well as prevents the further destruction of the teeth. ${ }^{12}$

According to Warren et al., there are two categories of patients: young and old. ${ }^{13}$ Young patients have a high predisposition to dental caries and it is exactly this category that benefits more from dental sealants. The other category is composed of older patients that are considered candidates for sealants, because of their reduced flow of saliva. The objective of sealants treatment is
${ }^{1}$ Department of Public Health, University of Vlora, Albania

${ }^{2,4}$ Department of Innovative Technologies in Medicine and Dentistry, University "Gabriele D'Annunzio" Chieti, Italy

${ }^{3}$ Department of Endodontic, University of Chieti, Italy

Corresponding Author: Mimoza Canga, Department of Public Health, University of Vlora, Albania, Phone: +355 676502493, e-mail: mimozacanga@hotmail.com

How to cite this article: Canga M, Malagnino G, Malagnino VA, et al. Effectiveness of Sealants Treatment in Permanent Molars: A Longitudinal Study. Int J Clin Pediatr Dent 2021;14(1):41-45.

Source of support: Nil

Conflict of interest: None

to prevent food collection and to create a geometric form of the teeth fissure. ${ }^{13}$

Most of the fissures have a degree of macro-tension, which makes place for the food waste to enter into the teeth. That is why the creation of micromechanics retention is required. Another reason why this retention is important is that sealants may be insufficient to reach the deeper parts of the teeth. ${ }^{14}$

Sealant is not very resistant to friction, it is flattened from the use of abrasive foods, but, the main areas of the tooth remain isolated good, which proves the positive continuous benefits of sealant treatment. ${ }^{14}$ 
The lack of knowledge on indications and effectiveness of sealants and the clinical experience of the dentists have a call into question the benefits of sealants treatment. These led dentists to suspend sealants treatment utilization, which brought in incomplete treatments. , $^{9,10,15}$

The main principle for sealant success is the right retention. The material of the sealants should be fluent to fill in the fissures and holes and to have sustainability to the fractures to resist the chewing forces and friction. ${ }^{14}$

The sealant must be well fixed not to create points of precontact or to interfere with the biting method. The success depends on the strength of the superficial layer of the sealant, and if this layer is intact there should be no reason for caries progress. ${ }^{15}$

Various studies showed that sealants may be used effectively in children, as long as the sealants are well preserved. ${ }^{16,17}$

Droz et al. pointed out that sealants treatment can reduce dental caries up to nine times. This fact along with the sealants' cost-effectiveness are some of the potential advantages of sealants treatment, which justify their use in the prevention of dental caries. ${ }^{18}$

The purpose of this study is to evaluate the reduction of dental caries within a period of 0-24 months and the clinical effects of dental sealants, used in the treatment of occlusive cavities, among children 6-11 years old.

\section{Materials and Methods}

The present clinical study is a longitudinal study conducted among children aged 6-11 years old. The overall sample was composed of 120 children, to whom we randomly chose 480 posterior teeth, which were divided into two groups:

Group I = 240 untreated teeth considered as the control group.

Group II $=240$ teeth underwent the sealant treatment.

The study participants were checked every 6 months. The study started in January 2019 and ended in January 2020. The study was conducted in five dental clinics in the city of Vlore, Albania.

The teeth of the first group did not undergo any treatment. They were just controlled by the dentists according to the periods chosen by this research, whereas the second group was treated with (UltraSeal XT ${ }^{\mathrm{TM}}$ hydro South Jordan, Utah, USA) according to the consecutive protocol. Acid etching was performed using $37 \%$ phosphoric acid gel (3M $\mathrm{M}^{\mathrm{TM}}$ Scotchbond ${ }^{\mathrm{TM}}$ Universal Etchant gel, Minnesota, USA), which was applied to the occlusal surface covering the teeth for 60 seconds.

To remove the acid etching completely, the teeth were rinsed with air-water spray for 15-20 seconds while the air-drying was done for 5 seconds with a three-way syringe. The sealant was applied for 10 seconds, after that, it was polymerized for 20-40 seconds. The dentists assured good retention and polymerization of the sealant before the children leaving. The treatment progress would be checked in the following visit.

Our study was conducted in accordance with the Helsinki declaration. ${ }^{19}$ Based on the Declaration of Helsinki issued by the World Medical Association, our research, which was on human participants, was clearly formulated in experimental protocols. In our study, we anticipated the benefits and the potential risks to our sample and after that, we took the consent of the children's parents. Permissions were obtained in the written form, which allowed us to perform the observations. Parents had the right to withdraw their children at any time.

The inclusion criterion was the age range 6-11 years old. The exclusion criteria were children must not have orthodontic brackets.
Children with enamel hypoplasia, dental fluorosis, and children who refused dental treatment were excluded from the study. Another limitation of the present study is the sample size, which was not large enough to generalize the results. The study had no dropouts. Six doctors participated in our study, four dentists and two assistants, who registered the children.

\section{Study Design}

This observational, analytical, and descriptive research was designed as a longitudinal study. The sample was not kept under hospital observation. After doing the treatment children were free to go. As we said the participants were selected through simple randomization and were invited to take part in the research. The inclusion criteria were in the age range of 6-11 years old. Informed written consent was obtained from all parents of the participants. This study was approved by the University of Vlora, Albania.

\section{Statistical Analysis}

Statistical analysis was performed using IBM SPSS Statistics 23.0. Data were analyzed by post hoc LSD test in analysis of variance (ANOVA). The significance level $(\alpha)$ was set at 0.05 with a confidence interval $(\mathrm{Cl})$ of $95 \%$.

\section{Results}

The data analysis showed that in the control group, there was an increment of dental caries (64.2\%) in the first and second molars, within the period 0-24 months. Based on the results, for the same period, in the group treated with sealant, we noticed that there was a decrease of dental caries (21.2\%). At the end of the study, in the treated group, there were 51 carious teeth, whereas, in the untreated group, there were 154. Based on the results, the number of carious teeth in the untreated group is three times higher than the number of carious teeth in the treated group (Table 1).

The distribution of caries in the control group within the period 0-24 months. The present study noticed that dental caries, in the control group, incremented to 154 (64.2\%) after 24 months, while $86(35.8 \%)$ teeth resulted without caries (Fig. 1).

The distribution of caries in the treated group within the period 0-24 months. In the treated group, 189 (78.8\%) teeth remained unaffected by caries and 51 (21.2\%) teeth were with caries (Fig. 2).

The present study proved that there is a significant correlation between time and caries manifestation $(p<0.05)$. In other words, time is a factor that increases the presence of caries (Table 2 ).

The treatment with sealant is an important preventive measure and very highly significant in caries reduction $(p=0.000)$ (Table 3 ).

Sealants application showed a high quality in the decrease of caries incidence with (78.8\%) in the treatment of first and second permanent molars.

Table 1: The increment of dental caries in the untreated and treated groups in the period of $0-24$ months

\begin{tabular}{cll}
\hline Time period & $\begin{array}{l}\text { Caries (untreated } \\
\text { group) (\%) }\end{array}$ & $\begin{array}{l}\text { Caries (treated group) } \\
(\%)\end{array}$ \\
\hline 0 month & $16(6.67)$ & $12(5)$ \\
6 months & $24(10)$ & $6(2.5)$ \\
12 months & $28(11.67)$ & $9(3.75)$ \\
18 months & $37(15.4)$ & $11(4.58)$ \\
24 months & $49(20.4)$ & $13(5.41)$ \\
& Total $=154(64.2)$ & Total $=51(21.2)$ \\
\hline
\end{tabular}




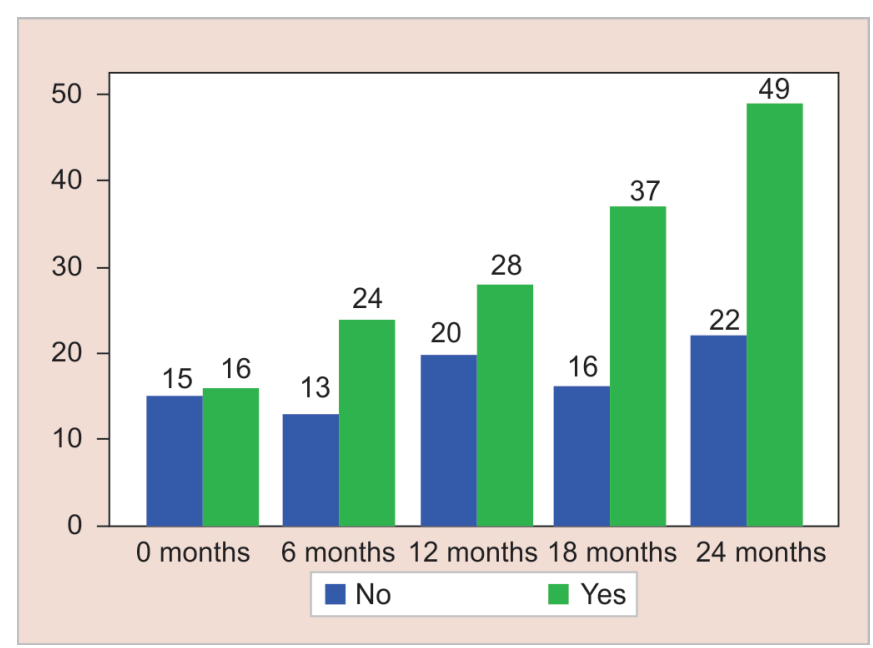

Fig. 1: The distribution of caries in the control group within the period 0-24 months

Table 2: The correlation between time period 0-24 months and caries manifestation

\begin{tabular}{lllll}
\hline Time period & $g L$ & $F$ & Cl 95\% & $p$ \\
\hline 0-24 months & 1 & 4.208 & $0.026-0.551$ & 0.03 \\
\hline
\end{tabular}

Table 3: The influence of sealant treatment in caries reduction

\begin{tabular}{lllll}
\hline $\begin{array}{l}\text { Sealant } \\
\text { treatment }\end{array}$ & $g L$ & $t$ & $F$ & $p$ \\
\hline & 1 & 5.83 & 110.8 & 0.000 \\
\hline
\end{tabular}

\section{Discussion}

Pit and fissure sealants were found to be an outstanding element to preventive strategies of oral healthcare in the decrease of occlusal caries on its initiation and progression. ${ }^{20}$

Properties of the pit and fissure sealants such as surface tension and viscosity are the most important factors that influence the penetration of the sealants. ${ }^{21}$ The use of sealants prevents the colonization of the bacteria and also inhibits the penetration of fermentable food waste remaining in the pits and fissures. ${ }^{22}$

According to Joseph and Donnell, pits and fissures' morphology causes them to be eight times more vulnerable to dental caries. ${ }^{23}$ Similar results were obtained by Mathewson and Primosch, who proved that the high incidence rate of pit and fissure caries is mainly due to its complex morphology which makes it an ideal site for the preservation of bacteria and residual food. ${ }^{24}$

Caries involving the occlusal surface of molars constitutes $52.7-66.3 \%$ of all carious lesions. ${ }^{25}$ Sanders et al. confirmed a strong correlation between the sealant treatment and the absence of caries. ${ }^{22}$

Cueto and Buonocore, in their study, proved that after the teeth were treated with sealant for 1 year, dental caries percentages declined to $86.3 \%$. The results above are similar to the ones obtained in the present study. ${ }^{26}$

In our survey, we have taken into consideration the sealants treatment as a prophylaxis study. This research chose to investigate 480 teeth from 120 children, where 240 teeth were treated with sealant, to generate precise conclusions on the effectiveness of

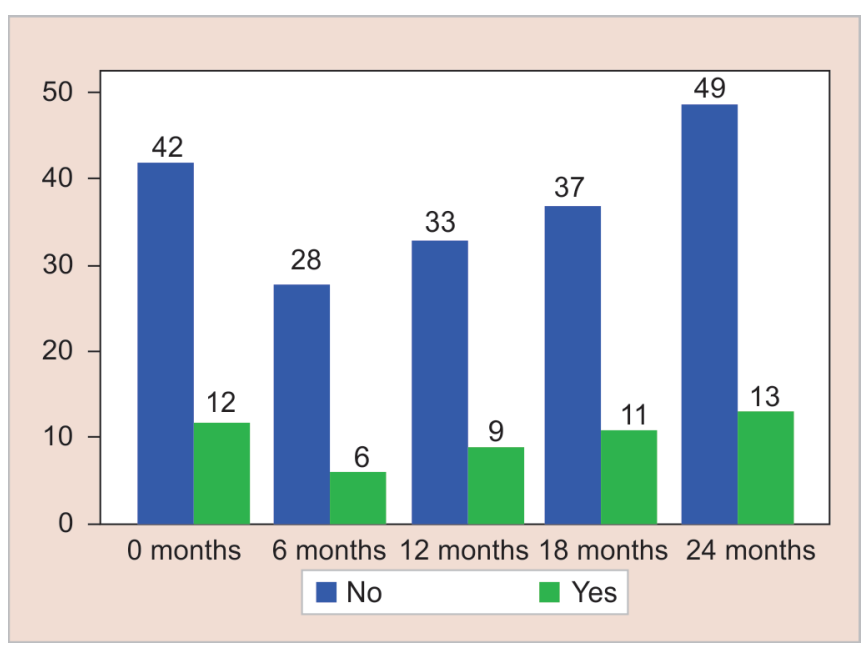

Fig. 2: The distribution of caries in the treated group within the period 0-24 months

sealants treatment. The results of this study showed that children treated with sealants developed caries $21.3 \%$, while in the control group caries developed in the values $64.2 \%$.

Similar studies about the effectiveness of sealants on reducing dental caries in the recesses and grooves of the posterior teeth emphasized that sealants should be used as dental caries preventive measure. ${ }^{10,11}$

In the United States, from 2011 to 2012, it was reported that $31.4 \%$ of 6 - to 8-year-old children had a fissure sealant. ${ }^{2}$ In Germany, a study among 8 - to 12 -year-old children showed that $55.6 \%$ of children had at least one fissure sealant applied. ${ }^{27}$

According to a study conducted on adolescents aged 12-18 years old in Portugal reported that $59 \%$ of the participants had the presence of at least one fissure sealant on FPMs. ${ }^{28}$

In contrast, a very low fissure sealants' prevalence was noted in 12- to 15-year-old Greek adolescents (8\%). ${ }^{29}$ In the Middle East, in Saudi Arabia, it was found that only $9 \%$ of adolescents had a minimum of one permanent molar sealed. ${ }^{30}$

To protect the teeth from dental caries, the sealing of pits and fissures can generally be recommended. Feigal and Donly claimed that as the emergence of caries has changed in the last decades, not only teeth in eruption should be sealed. ${ }^{31}$

The World Health Organization considers the pit and fissure sealants as the primary preventive and the most effective measure, to ensure the complete protection and the preservation of teeth from the carious phenomenon. ${ }^{32,33}$ This finding is similar to the claim of the present study and its contributions in the field of dentistry.

Sealants are a good preventive measure and they can inhibit the progression of carious lesions. They have important characteristics, such as the bio-compatibility and ease of use, which make these materials ideal products. ${ }^{34,35}$

According to the evidence-based guidelines of the American Dental Association (ADA), in collaboration with the American Academy of Paediatric Dentistry (AAPD), the use of sealants is recommended more than the fluoride varnish utilization or using no sealant at all. ${ }^{36,37}$

Sealants are considered to be more cost-effective if they are used to children at high risks of caries development or with teeth surfaces susceptible to caries. ${ }^{38}$ 
Based on the results of the present study, the number of carious teeth in the control group was three times higher than the number of carious teeth in the treated group. There is a significant decrease in dental caries if the teeth are sealed with sealants.

Within the limitations of our study, we suggest that sealants are considered to be a good preventive treatment, to decrease caries incidence and protect the teeth.

Another study conducted by Koulourides et al. claimed that if sealants are lost during patient visits they should be replaced, as sealants provide prevention of dental caries. ${ }^{39}$

According to the present study, sealing the teeth with sealants is considered to be highly effective in the prevention of caries in the first and the second permanent molars.

It is necessary to discuss the limitations of this research. We should have included a larger sample of children in this study, and also the period should have been longer. Another limitation that we can mention is the children's age range that this study took into consideration, which was 6-11 years old.

We highly recommend the use of pit and fissure sealants as a beneficial treatment. The main recommendations are that sealing pits and fissures of permanent posterior teeth is safe and effective, both in protecting and preserving the teeth. Dentists should therefore be encouraged to apply sealants.

Based on our results, we concluded that the sealants treatment reduces and prevents dental caries.

\section{CONCLUSION}

This study proved that sealant treatment is highly successful in reducing dental caries. In the future, it is worthwhile to go further in this research.

\section{Clinical Significance}

Dental caries is a problem in children aged 6-11 years old and not only. That is why this study recommends that sealants treatment should be used to prevent and reduce the prevalence of dental caries.

\section{ACKnowledgments}

I would like to thank my colleagues and particularly, professor Vito Malagnino, for his support and contribution in conducting this study.

\section{References}

1. Dye BA, Tan S, Smith V, et al. Trends in oral health status: United States, 1988-1994 and 1999-2004. Vital Health Stat 2007;11:1-92.

2. Dye BA, Thornton-Evans G, Li X, et al. Dental caries and sealant prevalence in children and adolescents in the United States 20112012. NCHS Data Br 2015;191:1-8.

3. Beltran-Aguilar ED, Barker LK, Canto MT, et al. Surveillance for dental caries, dental sealants, tooth retention, edentulism, and enamel fluorosis: United States, 1988-1994 and 1999-2002. MMWR Surveil Summ 2005;54:1-43.

4. Sun HB, Zhang W, Zhou XB. Risk factors associated with early childhood caries. Chin J Dent Res 2017;20(2):97-104.

5. Vermaire $\mathrm{JH}$. Parental attitudes towards oral health and caries-risk in their children. Int J Dent Hyg 2017;16(2):241-248. DOI: 10.1111/ idh.12296.

6. Albino J, Tiwari T, Gansky SA, et al. Early childhood caries collaborating centers. The basic research factors questionnaire for studying early childhood caries. BMC Oral Health 2017;17(1):83. DOI: 10.1186/s12903017-0374-5.

7. Nishi $M$, Harding $M$, Kelleher V, et al. Knowledge of caries risk factors/ indicators among Japanese and Irish adult patients with different socio-economic profiles: a cross-sectional study. BMC Oral Health 2017;17(1):55. DOI: 10.1186/s12903-017-0345-x.

8. Bhushan U, Goswami M. Evaluation of retention of pit and fissure sealants placed with and without air abrasion pretreatment in 6-8 year old children in vivo study. J Clin Exp Dent 2017;9(2):e211-e217. DOI: 10.4317/jced.53259.

9. Chestnutt IG, Playle R, Hutchings S, et al. Fissure seal or fluoride varnish? a randomized trial of relative effectiveness. J Dent Res 2017;96(7):754-761. DOI: 10.1177/0022034517702094.

10. Frazer RA, Platt JA, Sanders BJ, et al. The effect of fluoride varnish on enamel shear bond strength of pit and fissure sealants. Pediatr Dent 2017;39(2):155-158.

11. Deery C. Clinical practice guidelines proposed the use of pit and fissure sealants to prevent and arrest noncavitated carious lesions. J Evid Based Dent Pract 2017;17(1):48-50. DOI: 10.1016/j. jebdp.2017.01.008.

12. Ahovuo-Saloranta A, Hiiri A, Nordblad A, et al. Pit and fissure sealants for preventing dental decay in the permanent teeth of children and adolescents. Cochrane database of systematic reviews 2008. Caries Res 2017;5(4):34.

13. Warren $\mathrm{E}$, Curtis $\mathrm{BH}$, Jia N, et al. The caries management system: updating cost-effectiveness with 4-year post trial data. Int J Technol Assess Health Care 2016;32(3):107-115. DOI: 10.1017/ S0266462316000246.

14. Hilgert LA, Leal SC, Freire GML, et al. 3-year survival rates of retained composite resin and ART sealants using two assessment criteria. Braz Oral Res 2017;31(0):e35. DOI: 10.1590/1807-3107BOR-2017.

15. Chadwick BL. Seal or varnish? A randomized controlled trial to determine the relative cost and effectiveness of pit and fissure sealant and fluoride varnish in preventing dental decay. Health Technol Assess 2017;21(21):1-256. DOI: 10.3310/hta21210.

16. Mitchell ST, Funkhouser E, Gordan VV, et al. Satisfaction with dental care among patients who receive invasive or non-invasive treatment for non-cavitated early dental caries: findings from one region of the national dental PBRN. BMC Oral Health 2017;17(1):70. DOI: 10.1186/ s12903-017-0363-8.

17. Naaman R, El-Housseiny A, Alamoudi N. The use of pit and fissure sealants—a literature review. Dent J (Basel) 2017;5(4):34. DOI: 10.3390/ dj5040034.

18. Droz D, Schiele MJ, Panighi MM. Penetration and microleakage of dental sealants in artificial fissures. J Dent Child (Chic) 2004;71:41-44.

19. Williams JR. The declaration of helsinki and public health. Bull World Health Organ 2008;86(8):650-652. DOI: 10.2471/BLT.08.050955.

20. Abou El-Yazeed M, Abou-Zeid W, Zaazou M. Effect of different enamel pretreatment techniques for pit and fissure sealing in primary and permanent teeth. Aust J Basic Appl Sci 1991;7:895-899.

21. Burrow MF, Burrow JF, Makinson OF. Pits and fissures: etch resistance in prismless enamel walls. Aust Dent J 2001;46(4):258-262. DOI: 10.1111/j.1834-7819.2001.tb00289.x.

22. Sanders BJ, Feigal RJ, Avery DR. Pit and fissure sealants and preventive resin restorations. In: Mcdonald RE, Avery OR, Dean JA, ed. Dentistry for the Child and Adolescent. 8th ed., USA: Mosby; 2004;17: 353-363.

23. Joseph O, Donnell P, In vivo Evaluation of Embrace TM Wetbond TM Pit and Fissure Sealant; Internal Report 2003. Available from: http:// www.linkedin.com/pub/joseph-o-donnell/18/7A6/449.

24. Richard Mathewson J, Robert Primosch E. Fundamentals of pediatric dentistry. 3rd ed., Chicago, U.S: Quintessence Publishing Co; 2008. pp. 119-120.

25. Demirci M, Tuncer S, Yuceokur AA. Prevalence of caries on individual tooth surfaces and its distribution by age and gender in university clinic patients. Eur J Dent 2010;4(03):270-279. DOI: 10.1055/s-00391697839. 
26. Cueto El, Buonocore MG. Sealing of pits and fissures with an adhesive resin: its use in caries prevention. J Am Dent Assoc 1967;75(1):121-128. DOI: 10.14219/jada.archive.1967.0205.

27. Kühnisch J, Berger S, Goddon I, et al. Occlusal caries detection in permanent molars according to WHO basic methods, ICDAS II and laser fluorescence measurements. Community Dent Oral Epidemiol 2008;36(6):475-484. DOI: 10.1111/j.1600-0528.2008.00436.x.

28. Veiga NJ, Pereira CM, Ferreira PC, et al. Prevalence of dental caries and fissure sealants in a Portuguese sample of adolescents. PLoS ONE 2015;10(3):e0121299. DOI: 10.1371/journal.pone.0121299.

29. Oulis CJ, Berdouses ED, Mamai-Homata E, et al. Prevalence of sealants in relation to dental caries on the permanent molars of 12 and 15 -year-old Greek adolescents. A national pathfinder survey. BMC Public Health 2011;11(1):100. DOI: 10.1186/1471-2458-11-100.

30. Al Agili DE, Niazy HA, Pass MA. Prevalence and socioeconomic determinants of dental sealant use among schoolchildren in Saudi Arabia. East Mediterr Health J 2012;18(12):1209-1216. DOI: 10.26719/2012.18.12.1209.

31. Feigal RJ, Donly KJ. The use of pit and fissure sealants. Pediatr Dent 2006;28:143-150.

32. Hiiri A, Ahovuo-Saloranta A, Nordblad A, et al. Pit and fissure sealants versus fluoride varnishes for preventing dental decay in children and adolescents. Cochrane Database Syst Rev 2010;17:CD003067.
33. Beslot-Neveu A, Courson F, Ruse ND. Physico-chemical approach to pit and fissure sealant infiltration and spreading mechanisms. Pediatr Dent 2012;34:57-61.

34. Griffin SO, Oong E, Kohn W, et al. CDC dental sealant systematic review work group. The effectiveness of sealants in managing caries lesions. J Dent Res 2008;87(2):169-174. DOI: 10.1177/154405910808700211.

35. Wright JT, Crall JJ, Fontana M, et al. Evidence-based clinical practice guideline for the use of pit-and-fissure sealants: a report of the American Dental Association and the American Academy of Pediatric Dentistry. J Am Dent Assoc 2016;147(8):672-682. DOI: 10.1016/j. adaj.2016.06.001.

36. American Academy of Pediatric Dentistry. Evidence-based clinical practice guideline for the use of pit-and-fissure sealants. Pediatr Dent 2016;38:263-279.

37. American Academy of Pediatric Dentistry. Guideline on caries-risk assessment and management for infants, children, and adolescents. Pediatr Dent 2014;36:127-134.

38. Ahovuo-Saloranta A, Hiiri A, Nordblad A, et al. Sealants for preventing dental decay in the permanent teeth-a review. Cochrane Database Syst Rev 2013(3):CD001830. DOI: 10.1002/14651858.CD001830.pub4.

39. Koulourides T, Keller SE, Manson-Hing L, et al. Enhancement of fluoride effectiveness by experimental cariogenic priming of human enamel. Caries Res 1980;14(1):32-39. DOI: 10.1159/000260431. 